\title{
Sitosterol-mediated Antioxidant Regulation to Enhance Heat Tolerance in Creeping Bentgrass
}

\author{
Stephanie Rossi and Bingru Huang \\ Department of Plant Biology and Pathology, Rutgers, The State University of New Jersey, New \\ Brunswick, NJ 08901
}

\begin{abstract}
Additional INDEX words. Agrostis stolonifera, antioxidant metabolism, $\beta$-sitosterol, leaf senescence, membrane stability

Abstract. Heat stress symptoms in cool-season plants are characterized by loss of chlorophyll (Chl) and membrane stability, as well as oxidative damage. The objectives of this study were to determine whether foliar application of $\boldsymbol{\beta}$-sitosterol, a naturally occurring plant metabolite, may promote heat tolerance by suppressing heat-induced leaf senescence as indicated by the maintenance of healthy turf quality (TQ), and Chl and membrane stability; and to determine its roles in regulating antioxidant metabolism in creeping bentgrass (Agrostis stolonifera). 'Penncross' plants were exposed to heat stress $\left(35 / 30{ }^{\circ} \mathrm{C}\right.$ day/night) optimal temperature conditions (nonstressed control, $22 / 17^{\circ} \mathrm{C}$ day/night) for a duration of 28 days in environment-controlled growth chambers. Plants were foliar-treated with $\beta$-sitosterol $(400 \mu \mathrm{M})$ or water only (untreated control) before heat stress, and at 7-day intervals through 28 days of heat stress. Plants treated with $\beta$-sitosterol had significantly greater TQ and Chl content, and significantly less electrolyte leakage (EL) than untreated controls at 21 and 28 days of heat stress. Application of $\beta$-sitosterol reduced malondialdehyde (MDA) content significantly at 21 and 28 days of heat stress, and promoted the activities of superoxide dismutase (SOD), peroxidase (POD), catalase (CAT), and ascorbate peroxidase (APX) from 14 through 28 days of heat stress. $\beta$-Sitosterol effectively improved heat tolerance through suppression of leaf senescence in creeping bentgrass exposed to heat stress in association with the alleviation of membrane lipid peroxidation and activation of the enzymatic antioxidant system.
\end{abstract}

Heat stress is detrimental for cool-season turfgrasses and is characterized symptomatically by a marked decrease in TQ in cool-season turfgrass species as a result of heat-induced leaf senescence. Heat-induced leaf senescence is associated with loss of Chl and disruption of cellular membranes, leading electrolytes and ions to leak freely out of cells ( $\mathrm{Hu}$ et al., 2016; Liu and Huang, 2000; Wang et al., 2009; Wassie et al., 2019; Wilson et al., 2014). Membrane damage induced by heat stress and other abiotic stresses are associated with the production of reactive oxygen species (ROS), such as superoxide anion, hydrogen peroxide $\left(\mathrm{H}_{2} \mathrm{O}_{2}\right)$, and hydroxyl radical, that cause lipid peroxidation in plasma, mitochondria, peroxisome, and chloroplast membranes and are toxic to various macromolecules, such as lipids, proteins, and DNA (Hopkins, 1999; Jimenez et al., 1997; Roy and Basu, 2009). Lipid peroxidation occurs, producing MDA as ROS attack the conjugated double bonds of the unsaturated fatty acids comprising the liquid-disordered membranes (Berlett and Stadtman, 1997; Dean et al., 1997; Halliwell and Gutteridge, 1989). Antioxidant enzymes, including SOD, POD, CAT, and APX, play crucial roles in suppressing the production and accumulation of ROS and mitigate oxidative damage (Asada, 1999); however, severe heat stress can also damage antioxidant enzymes, restricting ROS scavenging ability (De la Haba et al., 2014). Because ROS exacerbate leaf senescence under stress, it is necessary to identify the mechanisms or natural metabolites

Received for publication 13 July 2021. Accepted for publication 6 Aug. 2021

Published online 19 November 2021

We thank the New Jersey Agricultural Experiment Station for support in funding this research.

B.H. is the corresponding author. E-mail: huang@sebs.rutgers.edu.

This is an open access article distributed under the CC BY-NC-ND license (https://creativecommons.org/licenses/by-nc-nd/4.0/). that may be effective in mitigating heat-induced oxidative damage.

Sterols are important components in membranes and play roles in maintaining membrane fluidity and stability (Dufourc, 2008; Hartmann, 1998). Phytosterols are present in high quantities in plant tissues, with $\beta$-sitosterol alone accounting for $\approx 50 \%$ of the total sterol content in leaves of various plant species (Nomura et al., 1999), including cool-season grass species such as hard fescue [Festuca trachyphylla (Wang et al., 2017)]. Seed priming or foliar spraying sterols have been found to have positive effects on improving plant tolerance to abiotic stresses, such as heat stress in tomato [Solanum lycopersicum (Gamel et al., 2017)], salt stress in pepper [Capsicum annuum (AbuMuriefah, 2015)] and sunflower [Helianthus annuus (Fawzia et al., 2016)], and drought stress in wheat [Triticum aestivum (Elkeilsh et al., 2019)] and white clover [Trifolium repens $(\mathrm{Li}$ et al., 2019)]. Sitosterol reinforces the stabilization of liquid-disordered membranes in plants exposed to heat stress (Dufourc, 2008). Sitosterol content correlated positively to heat tolerance of hard fescue, as demonstrated by its increased content in a heat-tolerant cultivar compared with a sensitive cultivar exposed to heat stress (Wang et al., 2017). Improvement of drought tolerance by exogenous application of $\beta$-sitosterol has been associated with increased total antioxidant capacity in white clover $(\mathrm{Li}$ et al., 2019) and antioxidant enzyme activities in wheat (Elkeilsh et al., 2019). $\beta$-Sitosterol, as a naturally occurring sterol molecule in plants, has been found to exhibit antioxidant potential for decreasing the level of ROS in animal cells by increasing the antioxidant activity of CAT, SOD, glutathione peroxidase, glutathione reductase, and glutathione S-transferase in rats [Rattus norvegicus (Baskar et al., 2012)]. The antioxidant functions of $\beta$-sitosterol against abiotic stress, including heat stress-induced oxidative damages in plants, are not well-understood. In 
addition, the manners in which foliar application of $\beta$-sitosterol may affect plant tolerance to heat stress by suppressing heatinduced leaf senescence and oxidative damage involving the regulation of enzymatic antioxidant metabolism have not been documented. Understanding how $\beta$-sitosterol may affect heat tolerance in cool-season turfgrass species involving the modulation of antioxidant metabolism is important for developing strategies in breeding selection or genetic modification and management practices to improve heat tolerance in cool-season turfgrass species.

Cool-season turfgrass species are widely grown in temperate climate regions, but they are sensitive to heat stress during summer months, and heat-induced leaf senescence and oxidative stress greatly hinder the performance of these species in warmclimate regions (Fry and Huang, 2004; Turgeon, 2002). The objectives of this study were to determine whether foliar application of $\beta$-sitosterol could promote heat tolerance by alleviating leaf senescence or maintaining $\mathrm{Chl}$ and membrane stability, as well as by enhancing antioxidant metabolism in creeping bentgrass (Agrostis stolonifera).

\section{Materials and Methods}

Plant materials and growth conditions. Sods of mature creeping bentgrass (cv. Penncross) (diameter, $10 \mathrm{~cm}$ ) were collected from field plots at a turfgrass research farm and planted immediately in 16 plastic pots (diameter, $15 \mathrm{~cm}$; height, $24 \mathrm{~cm}$ ) filled with sterilized sand. Plants were grown in a greenhouse for $28 \mathrm{~d}$ until root systems were established under natural sunlight, supplemented with sodium vapor lamps at average temperature conditions of $24 / 16^{\circ} \mathrm{C}$ (day/night). Turf was hand-trimmed twice weekly to maintain a canopy height of $3.8 \mathrm{~cm}$, and was irrigated to pot capacity on alternating days. Plants were fertilized on a biweekly basis with full-strength Hoagland's nutrient solution (Hoagland and Arnon, 1950). After the establishment period, plants were moved to environment-controlled growth chambers set to $22 / 17^{\circ} \mathrm{C}$ (day/night), $60 \%$ relative humidity, and a 14-h photoperiod with a photosynthetically active radiation value of $700 \mu \mathrm{mol} \cdot \mathrm{m}^{-2} \cdot \mathrm{s}^{-1}$, where they acclimated for $14 \mathrm{~d}$ before initiation of the experiment.

EXPERIMENTAL DESIGN AND TREATMENTS. Each plant was treated with either $40 \mathrm{~mL}$ of $400 \mu \mathrm{M} \beta$-sitosterol or $40 \mathrm{~mL}$ of water (untreated control) by foliar spraying until droplets formed, and then were exposed to optimal temperature (nonstressed control, $22 / 17^{\circ} \mathrm{C}$ day/night) or heat stress $\left(35 / 30^{\circ} \mathrm{C}\right.$ day/night) in growth chambers. This concentration of $\beta$-sitosterol was selected from a preliminary concentration screening test that showed it was the most effective in improving TQ under heat stress. $\beta$-Sitosterol treatments were applied subsequently every $7 \mathrm{~d}$ for the duration of the experiment ( $28 \mathrm{~d}$ ). The $\beta$-sitosterol or water treatment each consisted of four replicate plants per temperature treatment. Plants were placed in four growth chambers (Environmental Growth Chambers, Chagrin Falls, $\mathrm{OH}$ ), two controlled at $22 / 17^{\circ} \mathrm{C}$ and the other two at $35 / 30^{\circ} \mathrm{C}$, and were relocated across growth chambers twice per week to minimize the potentially confounding effects of variable environmental conditions among chambers. The experiment was carried out in a split-plot layout, with temperature (nonstress or heat stress) assigned as the main factor and chemical treatment $(\beta$-sitosterol or water) as the subfactor.
Physiological measurements. Several commonly used parameters, including TQ, leaf $\mathrm{Chl}$ content, and membrane stability, were evaluated to determine the effects of $\beta$-sitosterol on heat tolerance of plants or the extent of leaf senescence. TQ was rated visually every $7 \mathrm{~d}$ by assigning a value from 1 through 9 points depending on turf canopy color, density, and uniformity (Beard, 1972). On this scale, a rating of 9 points was designated to turf that was uniformly green and dense, whereas a rating of 1 point indicated turf that was completely brown, desiccated, and dead.

Using the methods of Hiscox and Israelstam (1979) with slight modifications, Chl content was analyzed every $7 \mathrm{~d}$ by immersing $0.1 \mathrm{~g}$ of fresh leaf tissue in $10 \mathrm{~mL}$ dimethyl sulfoxide and leaving the $\mathrm{Chl}$ to extract from the tissue in total darkness for $72 \mathrm{~h}$. After the extraction period, absorbance of the Chl solution was measured using a spectrophotometer (Thermo Fisher Scientific, Waltham, MA) at wavelengths of 663 and $645 \mathrm{~nm}$, and leaves were dried in a gravity convection oven (ColeParmer, Vernon Hills, IL) at $80^{\circ} \mathrm{C}$ for a minimum of $72 \mathrm{~h}$, after which dry weights were obtained. Chlorophyll content was calculated using the formulas provided by Arnon (1949).

To measure the stability of cell membranes, leaf EL was measured on a weekly basis by excising $\approx 0.1 \mathrm{~g}$ of mature leaves, cutting them into $1-\mathrm{cm}$ sections, and submerging them in a conical centrifuge tube containing $30 \mathrm{~mL}$ deionized water. Samples were shaken on an orbital shaker for $12 \mathrm{~h}$, and initial conductance was measured using a conductance meter (model 32; YSI, Yellow Springs, $\mathrm{OH}$ ). Leaves were killed by autoclaving at $121^{\circ} \mathrm{C}$ for $20 \mathrm{~min}$ and shaken again for a period of $12 \mathrm{~h}$, after which maximum conductivity was measured. EL was calculated as a ratio of initial conductance to maximum conductivity and was expressed as a percentage, according to the equations provided by Blum and Ebercon (1981).

EVALUATION OF LIPID PEROXIDATION AND ANTIOXIDANT ENZYME ACTIVITY. Fresh leaf tissue $(0.25 \mathrm{~g})$ collected at 7 -d intervals was flash-frozen in liquid nitrogen, ground mechanically into a fine powder using a mortar and pestle, and stored immediately at $-80^{\circ} \mathrm{C}$ in an ultra-low temperature freezer (Thermo Fisher Scientific) to be used in the lipid peroxidation and antioxidant enzyme activity reactions. A chilled extraction solution $(1 \mathrm{~mL})$ containing $50 \mathrm{~mm}$ phosphate buffer, $0.2 \mathrm{~mm}$ ethylenediaminetetraacetic acid (EDTA), and 1.0\% polyvinylpolypyrrolidone was added to the frozen leaf tissue and ground over ice for $\approx 5 \mathrm{~min}$, after which $2 \mathrm{~mL}$ of extraction solution was added to the slurry. After centrifuging the homogenate at $15,000 g_{n}$ at $4{ }^{\circ} \mathrm{C}$ for 20 min, the supernatant was decanted and saved to be used to measure MDA content and antioxidant enzyme activities.

The activity of SOD was determined using the methods of Giannopolitis and Ries (1977), with the modifications specified by Du et al. (2009). SOD-mediated inhibition of the photochemical reduction of Nitro blue tetrazolium chloride (NBT) was initiated by reacting the enzyme extract of each sample with a solution containing $50 \mathrm{~mm}$ phosphate buffer $(\mathrm{pH}, 7.8), 195 \mathrm{~mm}$ methionine, $60 \mu \mathrm{m}$ riboflavin, $3 \mu \mathrm{m}$ EDTA, and $1.125 \mathrm{~mm}$ NBT under fluorescent lighting for $20 \mathrm{~min}$. To halt the reaction, the solution was incubated in complete darkness for $10 \mathrm{~min}$, and SOD activity was measured immediately at $560 \mathrm{~nm}$ via spectrophotometer. One enzyme activity unit was expressed as the quantity of enzyme necessary for $50 \%$ inhibition of NBT photochemical reduction. The enzymatic activities of POD and CAT were measured using the procedure outlined in Chance and 
Maehly (1955), using the modifications detailed by $\mathrm{Du}$ et al. (2009). To analyze POD, crude enzyme extract from each sample was added to a solution comprised of $0.1 \mathrm{M}$ acetic acid-sodium acetate buffer $(\mathrm{pH}, 5.0)$ and $50 \%$ guaiacol, followed by the addition of $0.75 \% \mathrm{H}_{2} \mathrm{O}_{2}$ to initiate the reaction. To quantify the oxidation of guaiacol by $\mathrm{H}_{2} \mathrm{O}_{2}$, absorbance of the mixture was read via spectrophotometer at a wavelength of $460 \mathrm{~nm}$ every 10 $\mathrm{s}$ for $1 \mathrm{~min}$. A single unit of POD activity was represented by a decrease in absorbance by $1 \mathrm{U} \cdot \mathrm{min}^{-1}$. CAT activity was analyzed by combining crude enzyme extract with $50 \mathrm{~mm}$ phosphate buffer (pH, 7.0) with $45 \mathrm{~mm} \mathrm{H}_{2} \mathrm{O}_{2}$ and measuring the decomposition of $\mathrm{H}_{2} \mathrm{O}_{2}$ by CAT via spectrophotometer every $10 \mathrm{~s}$ for 1 $\mathrm{min}$ at a wavelength of $240 \mathrm{~nm}$. One unit of CAT enzyme was expressed as the decrease in absorbance by $0.01 \mathrm{U} \cdot \mathrm{min}^{-1}$. APX activity was analyzed using the methods of Nakano and Asada (1981), with certain alterations made to the procedure. To obtain an accurate measurement of APX activity, it was necessary to freeze fresh leaf tissue in liquid nitrogen, perform the extraction as detailed previously, and use the extract immediately. To quantify the oxidation of ascorbic acid by APX, the extract was mixed with $0.17 \mathrm{~mm}$ ascorbic acid, $100 \mathrm{~mm}$ acetic acid-sodium acetate buffer ( $\mathrm{pH}, 5.8), 0.05 \mu \mathrm{M}$ EDTA, and $0.08 \mathrm{~mm} \mathrm{H}_{2} \mathrm{O}_{2}$; the absorbance at $290 \mathrm{~nm}$ was read on a spectrophotometer every 10 s for $1 \mathrm{~min}$ (Du et al., 2013). An APX activity unit was defined as a change in absorbance by $0.01 \mathrm{U} \cdot \mathrm{min}^{-1}$.

To extract crude protein from each sample, $20 \% \mathrm{w} / \mathrm{v}$ trichloroacetic acid was added to the enzyme extract solution, and the mixture was rested at $4{ }^{\circ} \mathrm{C}$ for $\approx 1 \mathrm{~h}$ until protein precipitate
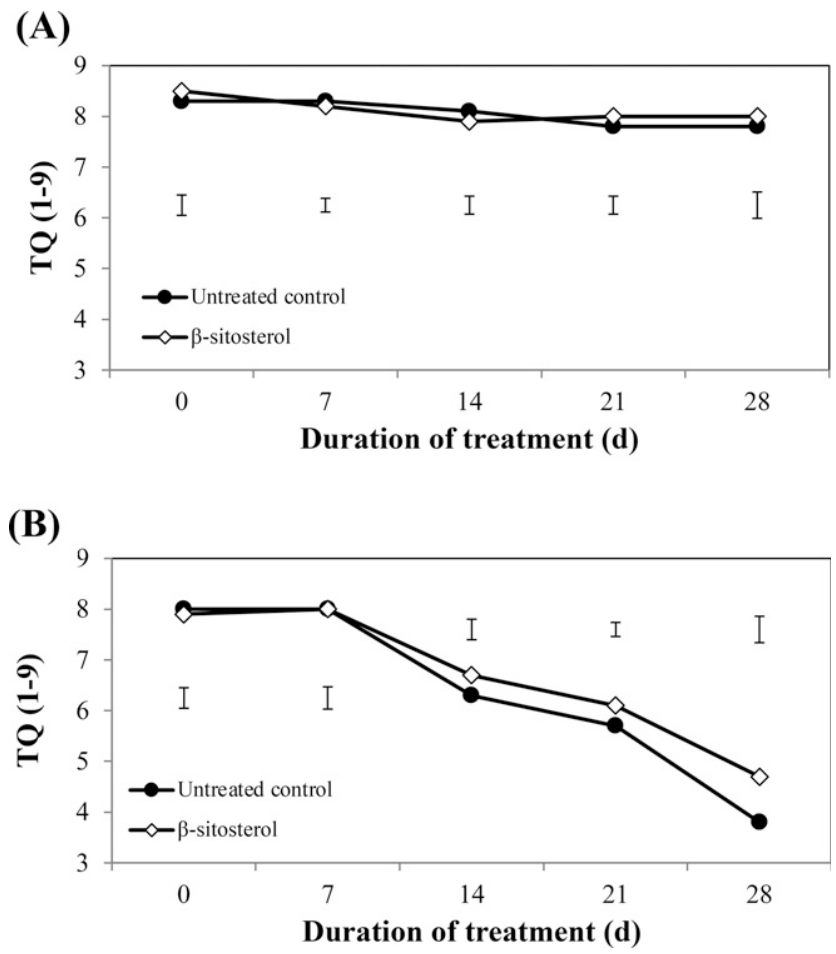

Fig. 1. Visual turf quality (TQ) ratings $(1=$ completely brown, desiccated, and dead; 9 = uniformly green and dense) for creeping bentgrass treated with $\beta$-sitosterol or untreated (control) under (A) nonstress or (B) heat stress conditions. Vertical bars define the SD of the means between treatments based on Fisher's protected least significant difference test $(P=$ 0.05 ) for each treatment date, where $\mathrm{n}$ is defined as the number of measurements represented by each value $(n=4)$. condensed at the bottom of the tube. After centrifuging the sample at $11,500 g_{n}$ for $15 \mathrm{~min}$, the supernatant was poured off and the pellet was air-dried and resuspended in $1.0 \mathrm{M}$ sodium hydroxide. A standard curve was constructed to quantify protein content, where bovine serum albumin was used as a standard and was diluted serially using Coomassie Brilliant Blue G-250 Dye (Bio-Rad Laboratories, Hercules, CA). To quantify protein content, the absorbance of the sample for each dilution factor was read at a wavelength of $595 \mathrm{~nm}$ on a spectrophotometer, and the absorbance values were applied to the standard curve to calculate protein content, which was then used to quantify the activities of antioxidant enzymes.

To quantify lipid peroxidation, the content of MDA was measured using the thiobarbituric acid reactivity procedure of Heath and Packer (1968), and using some of the methods detailed by Dhindsa et al. (1981), with slight modification. A reaction solution $(2 \mathrm{~mL})$ consisting of $20 \% \mathrm{w} / \mathrm{v}$ trichloroacetic acid and $0.5 \%$ w/v thiobarbituric acid was added to $1 \mathrm{~mL}$ enzyme extract, and the solution was heated for $30 \mathrm{~min}$ in a water bath at $95^{\circ} \mathrm{C}$. After cooling the solution rapidly to room temperature in ice water, tubes were shaken to remove gas bubbles and then centrifuged for $10 \mathrm{~min}$ at $10,000 g_{n}$. Using a spectrophotometer, absorbance of the supernatant was quantified at 532 and $600 \mathrm{~nm}$, and MDA concentration was calculated using an extinction coefficient of $155 \mathrm{~mm}^{-1} \cdot \mathrm{m}^{-1}$ (Heath and Packer, 1968; Kwon et al., 1965).

Statistical analysis. The significant effects of temperature and chemical treatments were determined by two-way analysis of variance using the general linear procedure with SAS (version 9.2; SAS Institute, Cary, NC). To define the differences between
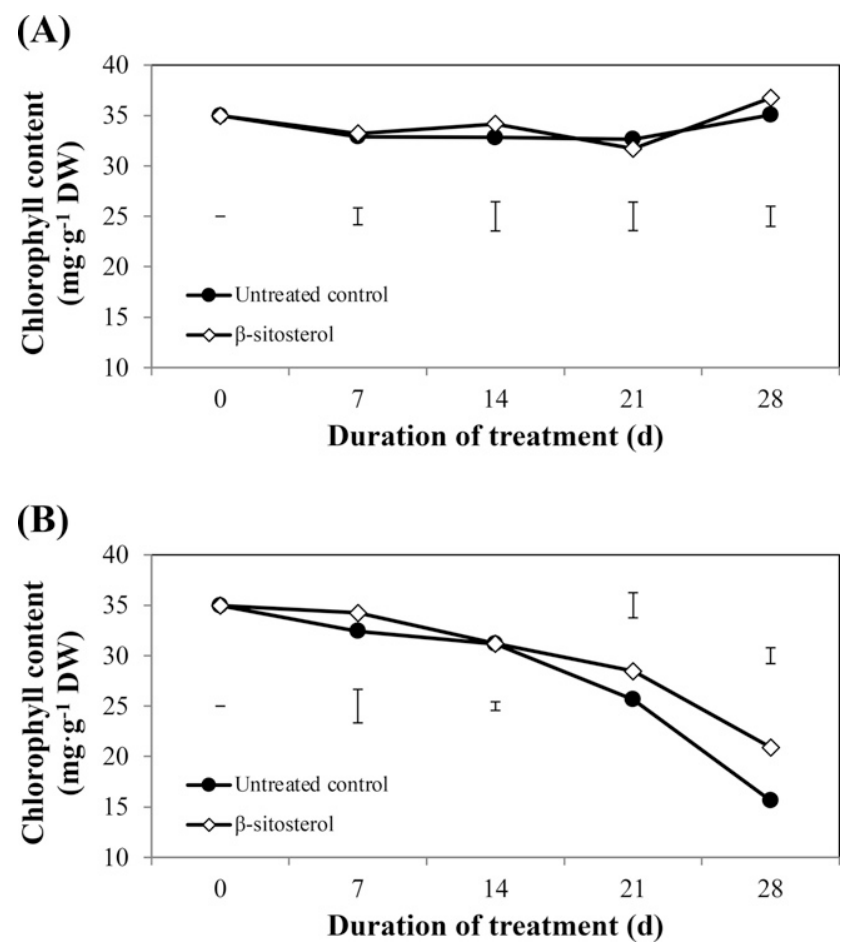

Fig. 2. Leaf chlorophyll content for creeping bentgrass treated with $\beta$-sitosterol or untreated (control) under (A) nonstress or (B) heat stress conditions. Vertical bars define the SD of the means between treatments based on Fisher's protected least significant difference test $(P=0.05)$ for each treatment date. where $\mathrm{n}$ is defined as the number of measurements represented by each value $(n=4)$. DW, dry weight. 
the mean values of treatments, Fisher's least significant difference test was used at a $0.05 P$ level.

\section{Results}

Physiological effects of $\beta$-Sitosterol ON THE SUPPRESSION OF HEAT-INDUCED LEAF SENESCENCE AND IMPROVEMENT OF HEAT TOLERANCE IN CREEPING BENTGRASS. Three commonly used physiological parameters, TQ, leaf Chl content, and leaf EL were evaluated as indicators of the level of leaf senescence and overall turf performance associated with heat tolerance. All three parameters remained unchanged in plants under normal temperature conditions (nonstress control), regardless of whether plants were treated with $\beta$-sitosterol (Figs. 1A, 2A, and 3A). There were no significant differences in any of these physiological parameters between the $\beta$-sitosterol treatment and untreated control under nonstress conditions.

TQ and leaf Chl content declined whereas leaf EL increased during heat stress in both $\beta$-sitosterol-treated plants and untreated control plants (Figs. 1B, 2B, and 3B); however, the decrease in TQ and leaf Chl content and increase in leaf EL was less pronounced in $\beta$-sitosterol-treated plants compared with the untreated control plants (Figs. 1B, 2B, and 3B).

Under heat stress, TQ was significantly greater in $\beta$-sitosterol-treated plants at 21 and $28 \mathrm{~d}$ of heat stress (by $7.02 \%$ and $23.68 \%$, respectively) in comparison with the untreated control (Fig. 1B). Leaf Chl content of plants treated with $\beta$-sitosterol was significantly greater than that of untreated controls at $21 \mathrm{~d}$ (by 10.98\%) and $28 \mathrm{~d}$ (by 33.81\%) (Fig. 2B).

(A)

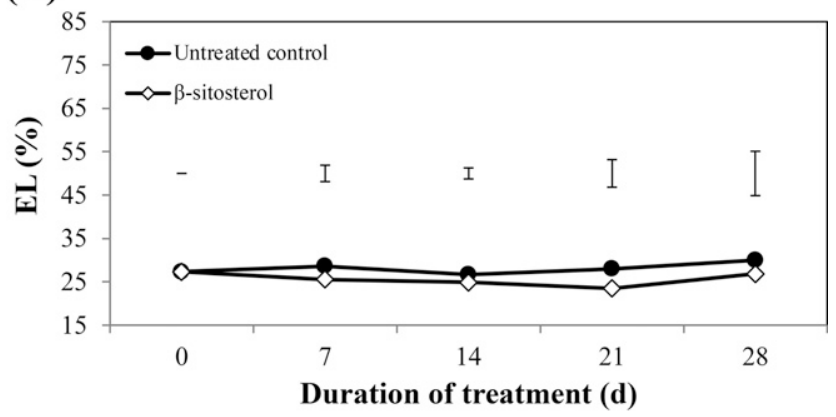

(B)

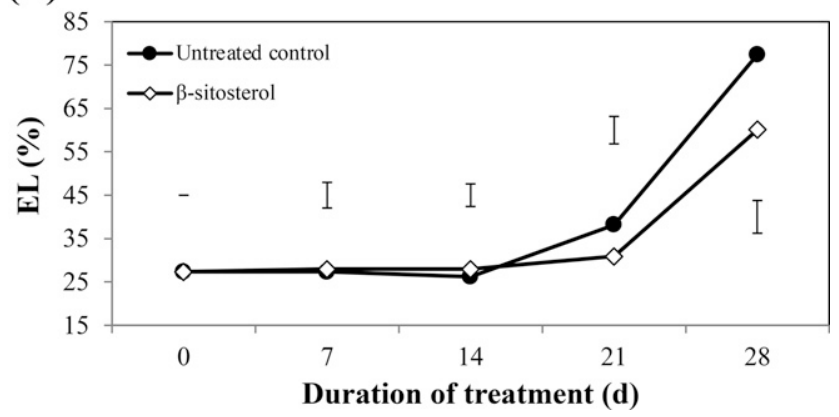

Fig. 3. Electrolyte leakage (EL) for creeping bentgrass treated with $\beta$-sitosterol or untreated (control) under (A) nonstress or (B) heat stress conditions. Vertical bars define the SD of the means between treatments based on Fisher's protected least significant difference test $(P=0.05)$ for each treatment date, where $\mathrm{n}$ is defined as the number of measurements represented by each value $(n=4)$.
Leaf EL was significantly less at 21 and $28 \mathrm{~d}$ of heat stress in plants treated with $\beta$-sitosterol (by $19.13 \%$ and $22.39 \%$, respectively) (Fig. 3B).

Alleviation OF HEAT-INDUCED LIPID PEROXIDATION AND ACTIVATION OF ANTIOXIDANT ENZYMES BY $\beta$-SITOSTEROL IN CREEPING BENTGRASS EXPOSED TO HEAT STRESS. Leaf MDA content remained unchanged during the experimental period $(28 \mathrm{~d})$ in $\beta$-sitosterol-treated plants and untreated control plants under nonstress control conditions (Fig. 4A). The content of MDA in leaves was not significantly different between the $\beta$-sitosterol treatment and untreated control under nonstress conditions (Fig. 4A).

The content of MDA in leaves increased gradually through the duration of heat stress $(28 \mathrm{~d})$, but to a greater extent in untreated control plants compared with that of $\beta$-sitosteroltreated plants (Fig. 4B). Plants treated with $\beta$-sitosterol had significantly less MDA content in leaves compared with the untreated control at $21 \mathrm{~d}$ (by $23.53 \%$ ) and $28 \mathrm{~d}$ (by 26.14\%) of heat stress (Fig. 4B).

The activities of SOD (Fig. 5A), POD (Fig. 5B), CAT (Fig. 5C), and APX (Fig. 5D) in leaves were unchanged under nonstress control conditions in all plants regardless of $\beta$-sitosterol treatment, and were unaffected by $\beta$-sitosterol under nonstress control conditions. Heat stress caused a decline in the activity of all antioxidant enzymes in leaves, but to a lesser extent in plants treated with $\beta$-sitosterol (Fig. 5A-D).

Under heat stress-at 14, 21, and $28 \mathrm{~d}$ of heat stress treatment- $\beta$-sitosterol application resulted in significant increases

\section{(A)}

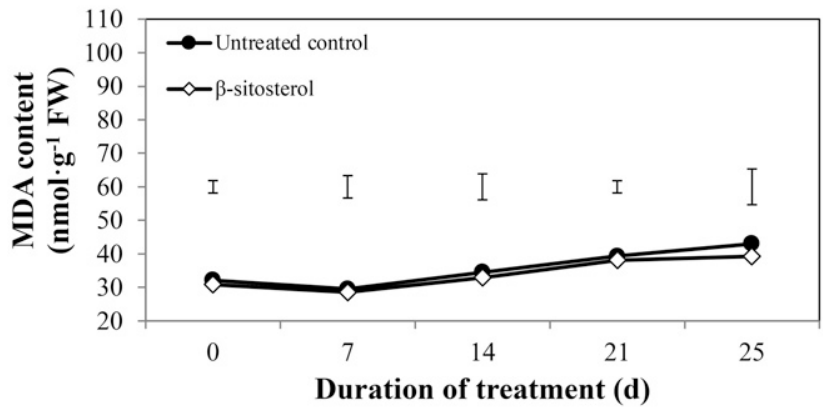

(B)

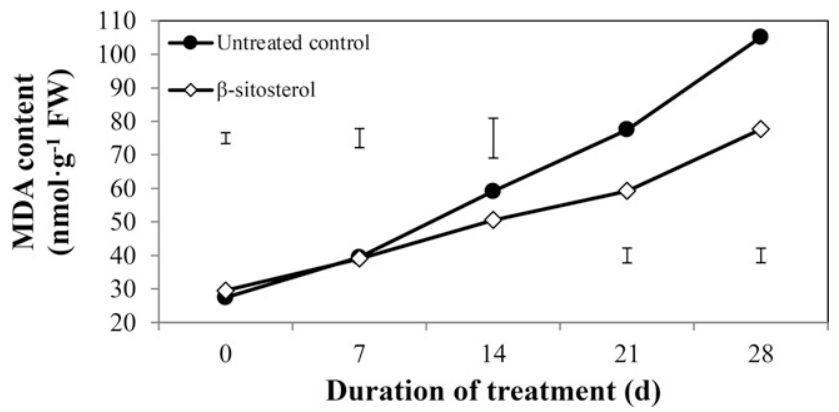

Fig. 4. Malondialdehyde (MDA) content as a measure of lipid peroxidation for $\beta$-sitosterol-treated or untreated (control) creeping bentgrass exposed to (A) nonstress or (B) heat stress conditions. Vertical bars define the SD of the means between treatments, and letters over bars indicate significant differences among chemical treatments at each treatment date based on Fisher's protected least significant difference test $(P=0.05)$, where $\mathrm{n}$ is defined as the number of measurements represented by each value $(\mathrm{n}=4)$. $\mathrm{FW}$, fresh weight. 
(A)

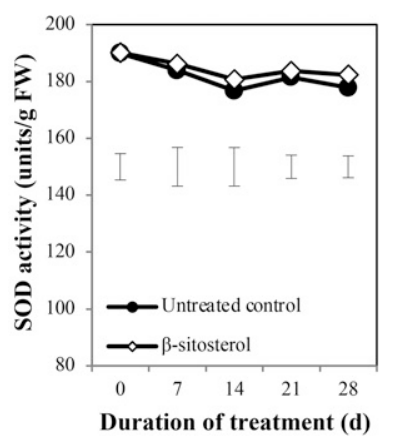

(C)

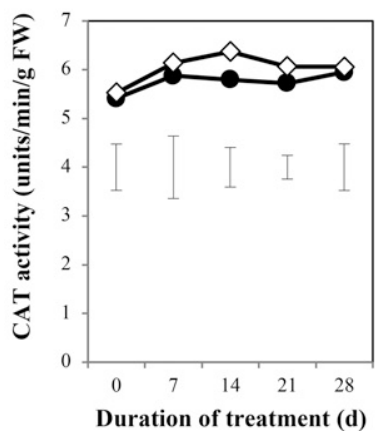

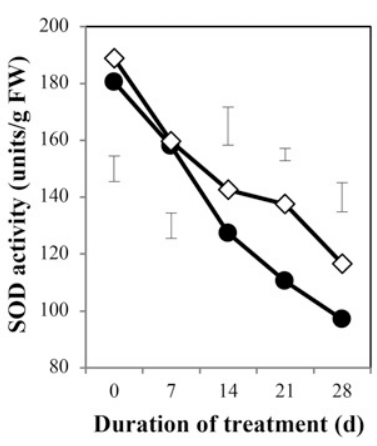

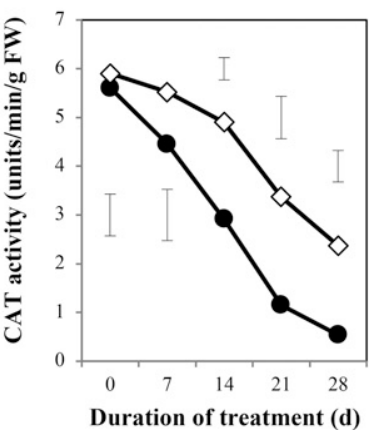

(B)
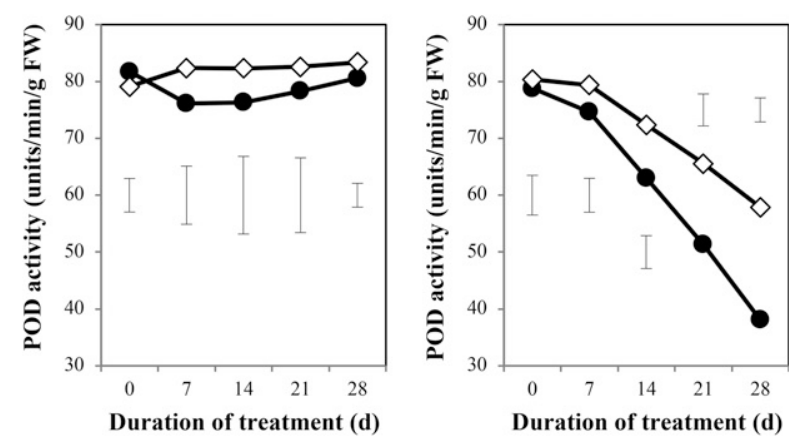

(D)

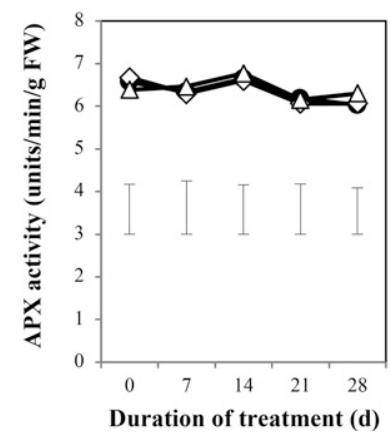

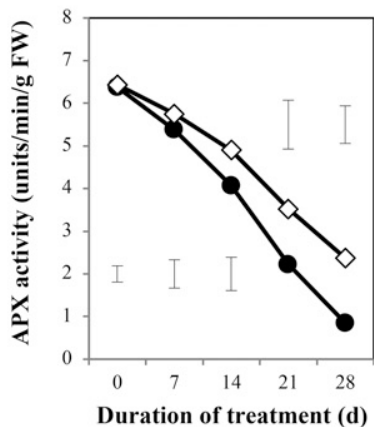

Fig. 5. Enzymatic activities for (A) superoxide dismutase (SOD), (B) peroxidase (POD), (C) catalase (CAT), and (D) ascorbate peroxidase (APX) in creeping bentgrass treated with $\beta$-sitosterol or untreated (control) under nonstress or heat stress conditions. Vertical bars define the SD of the means between treatments based on Fisher's protected least significant difference test $(P=0.05)$ for each treatment date, where $\mathrm{n}$ is defined as the number of measurements represented by each value $(\mathrm{n}=4)$.

in the activity of SOD [by $11.94 \%, 24.5 \%$, and $20.23 \%$, respectively (Fig. 5A)], POD [by $14.81 \%, 27.7 \%$, and $52 \%$, respectively (Fig. 5B)], CAT [by $67.99 \%, 191.59 \%$, and $340.56 \%$, respectively (Fig. 5C)], and APX [by 20.51\%, 58.4\%, and $178.88 \%$, respectively (Fig. 5D)] .

\section{Discussion}

Although positive effects of $\beta$-sitosterol on plant tolerance to abiotic stresses, including drought stress in white clover ( $\mathrm{Li}$ et al., 2019) and wheat (Elkeilsh et al., 2019), salt stress in pepper and sunflower (Abu-Muriefah 2015; Fawzia et al., 2016), and heat stress in tomato (Gamel et al., 2017), have been studied previously, this is the first study investigating how foliar application of $\beta$-sitosterol ameliorated heat-induced leaf senescence in association with mitigation of oxidative damage in a cool-season turfgrass species exposed to heat stress. The findings of our study indicate that foliar application of $\beta$-sitosterol suppressed heat-induced leaf senescence or improved heat tolerance of creeping bentgrass, as exhibited by increased TQ and Chl, and decreased EL in $\beta$-sitosterol-treated plants. The repression of heat-induced leaf senescence mediated by $\beta$-sitosterol may be attributed to the regulation of enzymatic antioxidant metabolism.

Sterols accumulate endogenously in various plant species under abiotic stresses and offer protection to membranes. $\beta$-Sitosterol accumulated in drought-tolerant rice (Oryza sativa), corresponding to an increased membrane stability index in drought-treated plants (Kumar et al., 2015). Although the effects of $\beta$-sitosterol on antioxidant enzymes are well-established in animal systems, documentation of the manners in which $\beta$-sitosterol contributes to the mitigation of abiotic stresses in plants is very limited. In an animal study, $\beta$-sitosterol was found to be an active antioxidant that prevented membrane lipid peroxidation and enhanced the levels of enzymatic antioxidants and nonenzymatic antioxidant compounds (Baskar et al., 2012). In wheat plants, it was reported that exogenous application of $\beta$-sitosterol alleviated drought stress by reducing MDA content and enhancing the activities of SOD, POD, CAT, and APX (Elkeilsh et al., 2019). In our study, $\beta$-sitosterol had no direct antioxidant effects when there was no oxidative stress, as antioxidant enzyme activities, MDA content, and EL in plants remained stable under nonstress conditions during the experimental period $(28 \mathrm{~d})$. However, $\beta$-sitosterol application increased the activities of SOD, POD, CAT, and APX in plants when heat stress reduced the activities of those enzymes in untreated controls. The enhanced activities of antioxidant enzymes corresponded to the $\beta$-sitosterol-reduced MDA content and EL under heat stress, indicating that $\beta$-sitosterol could have alleviated lipid peroxidation and improved antioxidant capacity when oxidative stress was induced by heat stress.

Among the antioxidant enzymes, CAT was most responsive to $\beta$-sitosterol, having the most pronounced increases in its activity during the entire heat stress period (by 3.4-fold at $28 \mathrm{~d}$ ). APX also had increased activities to a large extent (by 1.8-fold at $28 \mathrm{~d}$ ) in response to $\beta$-sitosterol application under heat stress. CAT, in the water-water cycle, and APX, in the ascorbate-glutathione cycle, play essential roles in reducing $\mathrm{H}_{2} \mathrm{O}_{2}$ into water. More specifically, CAT reacts directly with $\mathrm{H}_{2} \mathrm{O}_{2}$ to yield water and 
oxygen in the water-water cycle, whereas APX catalyzes the conversion of $\mathrm{H}_{2} \mathrm{O}_{2}$ to water and monodehydroascorbate using ascorbate as a substrate in the ascorbate-glutathione cycle (Asada, 1999; Zhang and Kirkham, 1996). Our results imply that $\beta$-sitosterol was most effective in detoxifying $\mathrm{H}_{2} \mathrm{O}_{2}$ by enacting the water-water cycle and the ascorbate-glutathione cycle of antioxidant metabolism against heat-induced oxidative stress.

In summary, our study demonstrated that $\beta$-sitosterol had positive effects in suppressing heat-induced leaf senescence or improving heat tolerance in creeping bentgrass involving activation of enzymatic antioxidant metabolism mainly in the water-water cycle and ascorbate-glutathione pathway, providing protective roles when antioxidant enzymes were damaged or when activities of these enzymes were reduced by heat stress. Our study suggests that $\beta$-sitosterol may be used as an effective agent to improve turfgrass performance through antioxidant protection against heat-induced oxidative stress in cool-season turfgrass species in the summer in warm-climate regions.

\section{Literature Cited}

Abu-Muriefah, S.S. 2015. Effect of sitosterol on growth, metabolism and protein pattern of pepper (Capsicum annuum L.) plants grown under salt stress conditions. Intl. J. Agr. Crop Sci. 8:94-106.

Arnon, D.I. 1949. Copper enzymes in isolated chloroplasts: Polyphenoloxidase in Beta vulgaris. Plant Physiol. 24:1-15, https://doi.org/ 10.1104/pp.24.1.1.

Asada, K. 1999. The water-water cycle in chloroplasts: Scavenging of active oxygens and dissipation of excess photons. Annu. Rev. Plant Biol. 50:601-639, https://doi.org/10.1146/annurev. arplant.50.1.601.

Baskar, A.A., K.S. Al Numair, M.G. Paulraj, M.A. Alsaif, M.A. Muamar, and S. Ignacimuthu. 2012. $\beta$-Sitosterol prevents lipid peroxidation and improves antioxidant status and histoarchitecture in rats with 1, 2-dimethylhydrazine-induced colon cancer. J. Med. Food 15:335-343, https://doi.org/10.1089/jmf.2011.1780.

Beard, J.B. 1972. Turfgrass: Science and culture. Regents/Prentice Hall, Englewood Cliffs, NJ.

Berlett, B.S. and E.R. Stadtman. 1997. Protein oxidation in aging, disease, and oxidative stress. J. Biol. Chem. 272:20313-20316, https:// doi.org/10.1074/jbc.272.33.20313.

Blum, A. and A. Ebercon. 1981. Cell membrane stability as a measure of drought and heat tolerance in wheat. Crop Sci. 21:43-47, https:// doi.org/10.2135/cropsci1981.0011183X002100010013x.

Chance, B. and A.C. Maehly. 1955. Assay of catalases and peroxidases. Methods Enzymol. 2:764-775, https://doi.org/10.1016/ S0076-6879(55)02300-8.

De la Haba, P., L. De la Mata, E. Molina, and E. Agüera. 2014. High temperature promotes early senescence in primary leaves of sunflower (Helianthus annuus L.) plants. Can. J. Plant Sci. 94:659-669, https://doi.org/10.4141/cjps2013-276.

Dean, R.T., S. Fu, R. Stocker, and M.J. Davies. 1997. Biochemistry and pathology of radical-mediated protein oxidation. Biochem. J. 324:1-18, https://doi.org/10.1042/bj3240001.

Dhindsa, R.S., P. Plumb-Dhindsa, and T.A. Thorpe. 1981. Leaf senescence: Correlated with increased levels of membrane permeability and lipid peroxidation, and decreased levels of superoxide dismutase and catalase. J. Expt. Bot. 32:93-101, https://doi.org/10.1093/jxb/ 32.1.93.

Du, H., Z. Wang, and B. Huang. 2009. Differential responses of warm-season and cool-season turfgrass species to heat stress associated with antioxidant enzyme activity. J. Amer. Soc. Hort. Sci. 134:417-422, https://doi.org/10.21273/JASHS.134.4.417.

Du, H., P. Zhou, and B. Huang. 2013. Antioxidant enzymatic activities and gene expression associated with heat tolerance in a cool-season perennial grass species. Environ. Exp. Bot. 87:159-166, https://doi. org/10.1016/j.envexpbot.2012.09.009.

Dufourc, E.J. 2008. The role of phytosterols in plant adaptation to temperature. Plant Signal. Behav. 3:133-134, https://doi.org/10.4161/ psb.3.2.5051

Elkeilsh, A., Y.M. Awad, M.H. Soliman, A. Abu-Elsaoud, M.T. Abdelhamid, and I.M. El-Metwally. 2019. Exogenous application of $\beta$-sitosterol mediated growth and yield improvement in waterstressed wheat (Triticum aestivum) involves up-regulated antioxidant system. J. Plant Res. 132:881-901, https://doi.org/10.1007/ s10265-019-01143-5.

Fawzia, A.E., A.E. Ashraf, A.H. Samia, A. El Hend, and F.S. Nora. 2016. $\beta$-Sitosterol ameliorates the chemical constituents of sunflower (Helianthus annuus L.) plants, grown under saline condition. IOSR J. Pharm. Biol. Sci. 11:36-45, https://doi.org/10.9790/3008-1103033645.

Fry, J. and B. Huang. 2004. Applied turfgrass science and physiology. Wiley, Hoboken, NJ.

Gamel, R.E., A. Elsayed, J. Bashasha, and S. Haroun. 2017. Priming tomato cultivars in $\beta$-sitosterol or gibberellic acid improves tolerance for temperature stress. Intl. J. Bot. 13:1-14, https://doi.org/10.3923/ ijb.2017.1.14.

Giannopolitis, C.N. and S.K. Ries. 1977. Superoxide dismutases: I. Occurrence in higher plants. Plant Physiol. 59:309-314, https://doi. org/10.1104/pp.59.2.309.

Halliwell, B. and J.M.C. Gutteridge. 1989. Free radicals in biology and medicine. 2nd ed. Oxford University Press, Oxford, UK, https:// doi.org/10.1016/0748-5514(85)90140-0.

Hartmann, M.A. 1998. Plant sterols and the membrane environment. Trends Plant Sci. 3:170-175, https://doi.org/10.1016/s1360-1385(98) 01233-3.

Heath, R.L. and L. Packer. 1968. Photoperoxidation in isolated chloroplasts: I. Kinetics and stoichiometry of fatty acid peroxidation. Arch. Biochem. Biophys. 125:189-198, https://doi.org/10.1016/0003-9861 (68)90654-1.

Hiscox, J.D. and G.F. Israelstam. 1979. A method for the extraction of chlorophyll from leaf tissue without maceration. Can. J. Bot. 57:1332-1334, https://doi.org/101139/b79-163.

Hoagland, D.R. and D.I. Arnon. 1950. The water-culture method for growing plants without soil. Calif. Agr. Exp. Stn. Circ. 347.

Hopkins, W.G. 1999. Introduction to plant physiology. 3rd ed. Wiley, Hoboken, NJ.

Hu, L., Z. Zhang, Z. Xiang, and Z. Yang. 2016. Exogenous application of citric acid ameliorates the adverse effect of heat stress in tall fescue (Lolium arundinaceum). Front. Plant Sci. 7:179, https://doi.org/ 10.3389/fpls.2016.00179.

Jimenez, A., J.A. Hernandez, L.A. del Río, and F. Sevilla. 1997. Evidence for the presence of the ascorbate-glutathione cycle in mitochondria and peroxisomes of pea leaves. Plant Physiol. 114:275-284, https://doi.org/10.1104/pp.114.1.275.

Kumar, M.S.S., K. Ali, A. Dahuja, and A. Tyagi. 2015. Role of phytosterols in drought stress tolerance in rice. Plant Physiol. Biochem. 96:83-89, https://doi.org/10.1016/j.plaphy.2015.07.014.

Kwon, T.W., D.B. Menzel, and H.S. Olcott. 1965. Reactivity of malonaldehyde with food constituents. J. Food Sci. 30:808-813, https:// doi.org/10.111/j.1365-2621.1965.tb01845.x.

Li, Z., B. Cheng, B. Yong, T. Liu, Y. Peng, X. Zhang, X. Ma, L. Huang, W. Liu, and G. Nie. 2019. Metabolomics and physiological analyses reveal $\beta$-sitosterol as an important plant growth regulator inducing tolerance to water stress in white clover. Planta 250:2033-2046, https://doi.org/10.1007/s00425-019-03277-1.

Liu, X. and B. Huang. 2000. Heat stress injury in relation to membrane lipid peroxidation in creeping bentgrass. Crop Sci. 40:503-510, https://doi.org/10.2135/cropsci2000.402503x.

Nakano, Y. and K. Asada. 1981. Hydrogen peroxide is scavenged by ascorbate-specific peroxidase in spinach chloroplasts. Plant Cell Physiol. 22:867-880, https://doi.org/10.1093/oxfordjournals.pcp. a076232. 
Nomura, T., Y. Kitasaka, S. Takatsuto, J.B. Reid, M. Fukami, and T. Yokota. 1999. Brassinosteroid/sterol synthesis and plant growth as affected by $1 \mathrm{ka}$ and $1 \mathrm{~kb}$ mutations of pea. Plant Physiol. 119:1517-1526, https://doi.org/10.1104/pp.119.4.1517.

Roy, B. and A.K. Basu. 2009. Abiotic stress tolerance in crop plants: Breeding and biotechnology. New India Publishing, New Delhi, India.

Turgeon, A.J. 2002. Turfgrass management. 6th ed. Pearson Education, London, UK.

Wang, J.Z., L.J. Cui, Y. Wang, and J.L. Li. 2009. Growth, lipid peroxidation and photosynthesis in two tall fescue cultivars differing in heat tolerance. Biol. Plant. 53:237-242, https://doi.org/10.1007/ s10535-009-0045-8.

Wang, J., H.R. Juliani, D. Jespersen, and B. Huang. 2017. Differential profiles of membrane proteins, fatty acids, and sterols associated with genetic variations in heat tolerance for a perennial grass species, hard fescue (Festuca trachyphylla). Environ. Exp. Bot. 140:65-75, https://doi.org/10.1016/j.envexpbot.2017.05.014.

Wassie, M., W. Zhang, Q. Zhang, K. Ji, and L. Chen. 2019. Effect of heat stress on growth and physiological traits of alfalfa (Medicago sativa L.) and a comprehensive evaluation for heat tolerance. Agronomy (Basel) 9:597, https://doi.org/10.3390/agronomy 9100597.

Wilson, R.A., M.K. Sangha, S.S. Banga, A.K. Atwal, and S. Gupta. 2014. Heat stress tolerance in relation to oxidative stress and antioxidants in Brassica juncea. J. Environ. Biol. 35:383.

Zhang, J. and M.B. Kirkham. 1996. Antioxidant responses to drought in sunflower and sorghum seedlings. New Phytol. 132:361-373, https://doi.org/10.1111/j.1469-8137.1996.tb01856.x. 